\title{
Estratégias de Aprendizagem Empregadas por Estudantes Universitários
}

\author{
Manuela Ramos Caldas Lins" \\ Universidade de Brasília, Brasília, Brasil
}

\begin{abstract}
RESUMO
Buscou-se identificar evidências de validade de uma escala de estratégias de aprendizagem para universitários, bem como o repertório de estratégias utilizado por tais estudantes. Participaram 341 alunos, de ambos os sexos, matriculados em uma universidade pública, com idade média de 19 anos e 7 meses (DP $=1,8)$. Os resultados foram obtidos mediante a aplicação individual de uma escala de estratégias de aprendizagem e indicaram a presença de 4 fatores, capazes de explicar $35,02 \%$ da variabilidade da escala. O Alfa de Cronbach revelou índice de consistência interna aceitável $(0,78)$. O teste $t$ apontou diferenças quanto ao uso de estratégias no que concerne ao sexo dos alunos. Sugere-se que novos estudos sejam realizados visando aprofundar os resultados ora apresentados.
\end{abstract}

Palavras-chave: ensino superior; estratégias de aprendizagem; propriedades psicométricas.

\section{ABSTRACT \\ Learning Strategies Used by a Group of Students of University}

This study has intended to investigate the evidence of validity of learning strategies scale for students of university, as well as the repertoire of strategies used by such students. Participated in this study 341 students, male and female, enrolled in a public university, with an average age of 19 years and 7 months $(\mathrm{SD}=1.8)$. The results were obtained by applying an individual of learning strategies scale and indicated the presence of four factors which can explain $35.02 \%$ of the variability of the scale. The Cronbach's alpha revealed acceptable internal consistency (0.78). The t-test showed differences in the use of strategies regarding the gender of the students. It is suggested that further studies to deepen the results presented here.

Keywords: higher education; learning strategies; psychometric properties.

Com advento da internet e das novas tecnologias, as pessoas estão cada vez mais envolvidas por uma rede complexa de informações, as quais se modificam de maneira rápida, demandando um processamento mental igualmente veloz. Nesse sentido, Bartalo (2006) e Bartalo e Guimarães (2006) afirmam que se tem exigido dos alunos que sejam mais ativos perante o conhecimento que lhes é oferecido, contudo, ainda não são oferecidas condições para que ajam de tal forma. Uma das maneiras de promover a atividade dos estudantes, segundo as autoras, é possibilitar que se debrucem sobre as tarefas, descobrindo seus objetivos e a forma mais eficaz de alcançá-los, o que pode ser feito via estratégias de aprendizagem.
Danserau (1985; Nisbett \& Shucksmith, 1987, citado por Pozo, 1996; Pozo, Monereo \& Castelló, 2004) concebe as estratégias de aprendizagem como sequências integradas de procedimentos ou atividades que se elegem com o propósito deliberado de facilitar a aquisição, o armazenamento e a utilização da informação. Dembo (1994) define as estratégias de aprendizagem como métodos que os estudantes utilizam para adquirir conhecimento. Silva e Sá (1997), por sua vez, acreditam que as estratégias de aprendizagem são processos conscientes, esquematizados pelos estudantes para atingirem objetivos de aprendizagem, sendo por essa razão processos controláveis e que podem facilitar realizações específicas. 
Há na literatura várias classificações e tipos de estratégias de aprendizagem. Dansereau e cols. (1979), por exemplo, acreditam que as estratégias de aprendizagem devem ser entendidas sob dois aspectos: estratégias primárias (se propõem a ajudar o aluno a organizar, elaborar e integrar a informação) e estratégias de apoio (são responsáveis pela manutenção de um estado interno satisfatório que favoreça a aprendizagem).

Weinstein e Mayer (1983) diferentemente identificaram cinco tipos de estratégias de aprendizagem: estratégias de ensaio (envolvem repetir ativamente o material a ser aprendido); estratégias de elaboração (implicam a realização de conexões entre o material novo a ser aprendido e o material antigo e familiar); estratégias de organização (referem-se à imposição de estrutura ao material a ser aprendido); estratégias de monitoramento (implicam que o indivíduo deve estar constantemente monitorando a sua capacidade de captar e absorver o conteúdo que está sendo ensinado); estratégias afetivas (referem-se à eliminação de sentimentos desagradáveis, que não condizem com a aprendizagem).

Zimmerman e Martinez-Pons (1986), diferentemente, encontraram 14 tipos de estratégias: autoavaliação, organização, transformação, estabelecimento de metas, planejamento, busca de informação, registro de informação, automonitoramento, organização do ambiente, busca de ajuda, revisão, ensaio, memorização, e por fim revisão de notas.

As estratégias de aprendizagem podem ainda ser classificadas como cognitivas ou metacognitivas. As estratégias cognitivas se referem a comportamentos e pensamentos que influenciam o processo de aprendizagem de maneira que a informação possa ser armazenada de forma mais eficiente. Enquanto que as estratégias metacognitivas são procedimentos que o indivíduo usa para planejar, monitorar e regular o seu próprio pensamento (Dembo, 1994).

A diversidade teórica quanto ao conceito de estratégias se manifesta na multiplicidade de instrumentos disponíveis para avaliá-las. No contexto nacional, muitos esforços têm sido realizados para desenvolver instrumentos confiáveis direcionados a mensurar as estratégias de aprendizagem. Nessa direção, Evely Boruchovitch e Acácia Santos, em 2001, com base na literatura internacional e em instrumentos como o Learning and Study Strategies Inventory, o Motivated
Strategies for Learning Questionnaire e a SelfRegulated Learning Interview Schedule, elaboraram uma escala destinada a avaliar as estratégias de aprendizagem utilizadas por universitários e posteriormente desenvolveram outra escala para mensurar as estratégias utilizadas por alunos do Ensino Fundamental.

No que concerne especificamente à escala para universitários, cabe dizer que esse instrumento já sofreu uma série de revisões, tendo sido utilizado por diversos pesquisadores brasileiros. De acordo com Boruchovitch (2006), a versão inicial da escala comportava 30 itens, em formato tipo likert de quatro pontos: sempre (4 pontos), às vezes ( 3 pontos), raramente ( 2 pontos) e nunca (1 ponto), com a pontuação variando de 30 a 120 pontos e 1 questão aberta que investigava a utilização de outras estratégias fora as mencionadas nos itens. Tal instrumento foi aplicado a 434 alunos universitários e a análise fatorial revelou a existência de cinco fatores, responsáveis por explicar 44\% da variância. Contudo, segundo a autora, esses fatores apresentavam algumas discrepâncias relacionadas às categorias tradicionais do construto e contradições em relação ao desempenho acadêmico.

Apesar disso, visando identificar o nível de compreensão em leitura e quais as estratégias de aprendizagem usadas por universitários, Sélis (2008) utilizou essa versão inicial (31 itens), mas com pontuações diferentes, a saber: sempre ( 3 pontos), às vezes ( 2 pontos), raramente ( 1 ponto) e nunca ( 0 ponto), sendo a pontuação mínima 0 e a máxima 90 pontos. Nesse estudo, os resultados gerais indicaram que os alunos dos períodos iniciais apresentaram pontuações mais elevadas do que os alunos concluintes.

Uma segunda versão do instrumento foi utilizada por Zenorini (2002) que buscou validar a escala de estratégias de aprendizagem, a qual após reformulações contava com 28 questões tipo likert com quatro opções de resposta (sempre, às vezes, raramente e nunca) e 1 questão aberta que investigava a utilização de outras estratégias fora as mencionadas nos itens. A análise fatorial exploratória indicou o agrupamento de quatro fatores: estratégias cognitivas de ensaio e elaboração, com 10 itens $(\alpha=0,80)$, estratégias metacognitivas, com 8 itens $(\alpha=0,73)$, estratégias cognitivas de organização, com 8 itens $(\alpha=0,67)$ e estratégias afetivas, com 2 itens $(\alpha=0,54)$. Como a questão 29 era optativa, ela foi excluída da análise fatorial e o Alfa de Cronbach da escala de 28 itens foi de 0,79 . 
Fazendo uso dessa versão do instrumento, Joly e Paula (2005), objetivando verificar o desempenho em compreensão em leitura dos universitários iniciantes, identificar a frequência no uso de estratégias e analisar possíveis relações entre essas duas variáveis e gênero, idade e curso frequentado, fizeram uma pesquisa junto a 201 estudantes de diferentes áreas do conhecimento. Os resultados apontaram escores mais elevados no fator estratégias cognitivas de ensaio e elaboração, demonstrando que essas são utilizadas com maior frequência pelos estudantes. E, além disso, diferença estatisticamente significante entre homens e mulheres, mas não em relação à faixa etária e ao curso foram observadas.

Em 2008, Muneiro, com a finalidade de avaliar o uso de estratégias de aprendizagem de alunos universitários e comparar o uso das estratégias entre os alunos da área de exatas e de humanas, fez uso da referida escala (versão 29 itens). Os resultados apontaram, de maneira geral, diferenças entre os alunos dos cursos de Serviço Social (humanas) e Engenharia de Produção (exatas). Por exemplo, os primeiros relataram usar mais frequentemente estratégias como "anotar na íntegra as explicações do professor", enquanto os segundos informaram usar com mais frequência estratégias como "analisar gráficos e tabelas".

Com o intuito de descrever as estratégias de aprendizagem e de regulação de 298 estudantes universitários, Bortoletto (2011) usou uma versão diferente da escala, com 49 itens fechados, os quais variavam entre sempre ( 3 pontos), às vezes ( 2 pontos), raramente ( 1 pontos) e nunca (0 ponto), sendo a pontuação invertida em alguns itens. Os 49 itens encontravam-se distribuídos em três fatores: Estratégias cognitivas (19 itens), estratégias metacognitivas (23 itens) e ausência de estratégias metacognitivas disfuncionais ( 7 itens). A pontuação total da escala variava de 49 a 196 pontos. Os resultados mostraram diferenças significativas quando comparado o sexo dos participantes, tendo as mulheres alcançado pontuações mais elevadas em todas as subescalas do instrumento e, além disso, que estudantes mais velhos saíram-se melhor do que os mais jovens, alcançando escores mais altos nas três subescalas e consequentemente na escala como um todo.

Em uma nova revisão, Santos e Boruchovitch (2011) modificaram o instrumento, com base nos estudos anteriores e esse passou a contar com 36 itens, em formato tipo likert de quatro pontos: sempre (3 pontos $)$, às vezes ( 2 pontos $)$, raramente ( 1 ponto) $\mathrm{e}$ nunca (0 ponto), com pontuação total variando de 0 a 108. Por esse estudo os itens agruparam-se em três fatores, distribuídos da seguinte forma: Fator 1 - Autorregulação Cognitiva e Metacognitiva, com 24 itens referentes às estratégias de aprendizagem cognitivas e metacognitivas existentes na literatura; Fator 2 - Autorregulação dos Recursos Internos e Contextuais, com 8 itens referentes ao conjunto de estratégias orientadas para o controle e o manejo dos estados internos e das variáveis contextuais que interferem na aprendizagem autorregulada; e no Fator 3 - Autorregulação Social, 4 itens relativos às estratégias orientadas às formas de aprendizagem que envolvem a relação e a interação com o outro. A escala foi aplicada em 1.490 estudantes universitários e apresentou alta consistência interna $(\alpha=0,88)$. Quanto às subescalas, no Fator 1 o alfa de Cronbach foi de 0,87, no Fator 2 $\alpha=0,70$ e no Fator $3 \alpha=0,65$.

A partir dessa nova formatação do instrumento e visando dar continuidade às pesquisas, Alcará (2012), tendo como finalidade caracterizar os universitários quanto ao uso de estratégias de aprendizagem, compreensão de leitura e orientações motivacionais, dentre outras, aplicou o instrumento a 110 estudantes. De forma global, os resultados concernentes às estratégias de aprendizagem indicaram que os estudantes utilizavam de forma razoável as estratégias e que não foram verificadas diferenças significativas em relação ao curso, série, sexo e faixa etária. Ao fim do estudo, sugeriu que novas investigações fossem feitas, uma vez que os dados obtidos permitiram atribuir evidências de validade apenas para parte das medidas utilizadas.

Silva (2012) com o objetivo de verificar se o estilo de aprendizagem dos estudantes universitários mantinha-se relacionado às estratégias de aprendizagem, administrou a escala em sua versão de 49 itens, mas após saber da redução do instrumento, excluiu treze itens das análises e considerou apenas os 36 que compõe a versão atual do instrumento. Os resultados apontaram haver uma ordem hierárquica no uso preferencial das estratégias de aprendizagem e, além disso, indicaram diferenças estatisticamente significantes entre as áreas de conhecimento e o gênero dos participantes em pelo menos um dos três fatores do instrumento. 
Com base nesses dados e tendo em vista que as estratégias de aprendizagem influenciam o êxito e a qualidade da aprendizagem, este trabalho objetivou investigar evidências de validade da escala de estratégias de aprendizagem para estudantes universitários, de autoria de Acácia Santos e Evely Boruchovitch, bem como a maneira como essas estratégias estão sendo mais frequentemente empregadas por tais alunos. Pretendeu-se verificar também a existência de diferenças no uso das estratégias no que se refere ao sexo e as áreas do conhecimento.

\section{MÉTODO}

\section{Participantes}

O estudo foi realizado com 341 alunos universitários matriculados em uma universidade pública do Distrito Federal. O sexo feminino representou 59,8\% $(n=204)$ da amostra e o masculino 40,2\% $(n=137)$. A média de idade foi de 19 anos e 7 meses $(\mathrm{DP}=1,8)$, sendo a idade máxima de 25 anos e a mínima de 16 anos. Do total de alunos, 40,5\% $(\mathrm{n}=138)$ eram da área de exatas, 49,3\% ( $n=168)$ de humanas e $10,3 \%(n=35)$ da saúde.

\section{Instrumento}

Utilizou-se a Escala de Avaliação de Estratégias de Aprendizagem para Universitários (Santos \& Boruchovitch, 2011), que tem por objetivo avaliar as estratégias de aprendizagem utilizadas por alunos do ensino superior. Tal escala, contém 36 questões, em formato likert, com quatro possibilidades de respostas para cada uma das questões. As categorias são descritas como: sempre, valendo 3 pontos; às vezes, 2 pontos; raramente, 1 ponto; e, nunca, 0 ponto. A pontuação mínima da escala é de 0 e a máxima é de 108 pontos.

Como referido anteriormente, nessa versão da escala os itens agruparam-se em três fatores, distribuídos da seguinte forma: Fator 1 - Autorregulação Cognitiva e Metacognitiva, com 24 itens $(\alpha=0,87)$; Fator 2 - Autorregulação dos Recursos Internos e Contextuais, com 8 itens $(\alpha=0,70)$; e no Fator 3 - Autorregulação Social, 4 itens $(\alpha=0,65)$, tendo a escala total apresentado alta consistência interna $(\alpha=0,88)$.

\section{Procedimentos}

Após a escolha, por conveniência, da instituição onde a pesquisa seria realizada, os participantes foram selecionados de forma não probabilística. A esses foi explicada a pesquisa, de modo tal que foi esclarecido o objetivo e como seria realizada a coleta. Além disso, que poderiam desistir em qualquer etapa sem sofrer penalizações, que os dados oriundos da pesquisa seriam mantidos em sigilo e o anonimato, quando da divulgação dos resultados, seria garantido, conforme prevê os padrões éticos de conduta dispostos na resolução 196/96. Mediante o aceite em participar, foi entregue aos estudantes o instrumento para que respondessem de forma individual. Permaneceu-se próximo a eles para que fosse possível sanar dúvidas, tanto de conteúdo quanto de forma, caso surgissem. A aplicação ocorreu nos meses de maio e junho de 2012 e durou aproximadamente 15 minutos por respondente.

\section{RESULTADOS}

Os dados coletados foram tabulados e submetidos às estatísticas descritivas e inferenciais, visando atender os objetivos propostos, com o auxílio do pacote estatístico SPSS na versão 19 para Windows. Como a distribuição da população foi normal, utilizou testes paramétricos e o nível de significância adotado foi de 5\%.

No que concerne às propriedades psicométricas da escala, inicialmente, para verificar se haveria a possibilidade de aplicar a análise fatorial exploratória, realizou-se o Teste de Esfericidade de Bartlett, o qual indicou que a matriz de correlação não era uma matriz de identidade, existindo uma correlação entre os itens $\left(X^{2}[630 ; N=341]=2707,469 ; p<0,001\right)$. A medida de adequação da amostra, averiguada pelo índice de Kaiser-Meyer-Olkin (KMO), foi de 0,75. Os dados obtidos revelaram existir um nível de probabilidade adequado para a correlação entre variáveis e que a amostra era apropriada para a realização da Análise Fatorial.

Então fez-se uma extração dos componentes principais e após uma análise da variância explicada, do critério de raiz latente que considera significantes apenas os eigenvalues maiores que um, dos valores extraídos do gráfico scree plot, bem como uma avaliação da análise paralela, optou-se por considerar quatro fatores, capazes de explicar $35,02 \%$ da variância total. Contudo, com o objetivo de estabelecer um comparativo entre os dados da presente pesquisa e os obtidos no estudo de validação, primeiramente considerou-se três fatores, os quais no estudo original foram intitulados: Autorregulação Cognitiva e Metacognitiva, Au- 
torregulação dos Recursos Internos e Contextuais, e Autorregulação Social. Com esses, explicou-se 29,2\% da variância e os itens agruparam-se de maneira diferente do estudo original, pouco congruente teoricamente. O único fator que se comportou de forma similar em ambos os estudos foi o que trata dos recursos internos e contextuais, uma vez que no trabalho original comportava 8 itens $(12,18,19,20,22,23,24$ e 27) e no presente trabalho, 9 itens $(11,12,13,18,19$, 20, 23, 24 e 27).

Após essa análise inicial para fins comparativos, considerou-se os quatro fatores, onde além de obter mais variância explicada, obteve-se mais coerência teórica. Assim, rodou-se a análise por componentes principais e rotação varimax. Como pode ser visto na Tabela 1, os fatores ficaram distribuídos da seguinte maneira: Fator 1 - Estratégias de Armazenamento da Informação, com 8 itens (1, 2, 4, 6, 7, 30, 31 e 32); Fator 2 - Estratégias de Controle Interno e Externo, com 9 itens $(12,13,18,19,20,22,23,24$ e 27); Fator 3 - Estratégias de Busca e Seleção da Informação, com 6 itens $(8,10,21,25,26$ e 36); e Fator 4 - Estratégias de Interação Social, com 4 itens $(17,29,33$ e 34).

Tabela 1

Distribuição dos itens por fator e suas respectivas cargas fatoriais e comunalidades

\begin{tabular}{|c|c|c|c|c|c|}
\hline & 1 & 2 & 3 & 4 & Comunalidades \\
\hline 1. Repetir as informações oralmente na medida em que vai lendo o texto. & 0,425 & & & & 0,276 \\
\hline 2. Anotar na íntegra as explicações do professor. & 0,523 & & & & 0,297 \\
\hline 4. Resumir os textos indicados para estudo. & 0,546 & & & & 0,343 \\
\hline 6. Fazer anotações no texto ou em folha à parte. & 0,579 & & & & 0,374 \\
\hline 7. Escrever com suas palavras o que entendeu do texto. & 0,459 & & & & 0,286 \\
\hline 30. Anotar na agenda as coisas que tem para fazer. & 0,600 & & & & 0,439 \\
\hline $\begin{array}{l}\text { 31. Fazer algum esquema no papel (esboço, gráfico ou desenho) para melhor } \\
\text { entender as relações entre eles. }\end{array}$ & 0,387 & & & & 0,236 \\
\hline 32. Colar lembretes para recordar do que precisa fazer. & 0,531 & & & & 0,355 \\
\hline 12. Controlar sua ansiedade em situações de avaliação. & & 0,650 & & & 0,550 \\
\hline 13. Identificar o quanto você está ou não aprendendo. & & 0,588 & & & 0,438 \\
\hline 18. Administrar seu tempo de estudo. & & 0,603 & & & 0,479 \\
\hline 19. Organizar seu ambiente de estudo. & & 0,609 & & & 0,537 \\
\hline 20. Manter a calma diante de tarefas difíceis. & & 0,564 & & & 0,456 \\
\hline 22. Planejar suas atividades de estudo. & & 0,564 & & & 0,528 \\
\hline 23. Separar todo o material necessário para a tarefa que irá realizar. & & 0,462 & & & 0,336 \\
\hline 24. Conseguir ir até o final de uma tarefa mesmo quando ela é difícil ou tediosa. & & 0,473 & & & 0,343 \\
\hline $\begin{array}{l}\text { 27. Distrair-se ou pensar em outra coisa quando está lendo, estudando ou } \\
\text { fazendo os trabalhos. }\end{array}$ & & 0,350 & & & 0,195 \\
\hline 8. Ler textos complementares, além dos indicados pelo professor. & & & 0,613 & & 0,403 \\
\hline 10. Elaborar perguntas e respostas sobre o assunto estudado. & & & 0,450 & & 0,246 \\
\hline 21. Recorrer a outros textos e livros sobre o assunto. & & & 0,547 & & 0,312 \\
\hline 25. Verificar seus erros após receber uma nota de prova. & & & 0,525 & & 0,333 \\
\hline 26. Tentar refazer questões que errou em uma prova. & & & 0,612 & & 0,395 \\
\hline 36. Criar perguntas sobre o assunto que está estudando e tentar respondê-las. & & & 0,504 & & 0,349 \\
\hline 17. Pedir ajuda aos colegas em caso de dúvidas. & & & & 0,609 & 0,400 \\
\hline 29. Estudar em grupo. & & & & 0,661 & 0,467 \\
\hline 33. Discutir a matéria com os colegas para ver se entendeu. & & & & 0,703 & 0,518 \\
\hline 34. Pedir para alguém tomar a matéria. & & & & 0,507 & 0,316 \\
\hline
\end{tabular}

Salienta-se que dos 36 itens, nove apresentaram-se problemáticos, tendo em vista que cinco itens carregaram, com valores muito próximos (menos de 0,10 ) entre si, em mais de um fator $(3,5,14,15$ e 35). Três itens claramente carregaram em fator não congruente teoricamente $(9,11$, e 28) e um deles apresentou carga fatorial abaixo do recomendado pela literatura (16). $\mathrm{Na}$ Tabela 2, têm-se esses itens e suas respectivas cargas fatoriais e comunalidades. 
Tabela 2

Itens excluídos da análise e suas respectivas cargas e comunalidades

\begin{tabular}{|c|c|c|c|c|c|}
\hline & 1 & 2 & 3 & 4 & Comunalidades \\
\hline $\begin{array}{l}\text { 3. Identificar suas dificuldades para aprender determinados tópicos ou } \\
\text { assuntos. }\end{array}$ & & 0,341 & 0,316 & & 0,283 \\
\hline 5. Ler os textos indicados pelo professor. & 0,287 & & 0,353 & & 0,337 \\
\hline 9. Motivar-se para as atividades de leitura e estudo. & & & 0,472 & & 0,326 \\
\hline 11. Selecionar as ideias principais do texto & & 0,385 & & & 0,239 \\
\hline 14. Pedir auxílio ao professor sobre as dúvidas na matéria & & & 0,397 & 0,425 & 0,341 \\
\hline 15. Rever as anotações feitas em sala de aula & 0,297 & 0,283 & 0,280 & 0,209 & 0,291 \\
\hline 16. Procurar no dicionário o significado de palavras desconhecidas & & & 0,265 & & 0,085 \\
\hline 28. Ler suas respostas novamente antes de entregar a prova & & & & 0,410 & 0,222 \\
\hline 35. Reler a matéria para entendê-la melhor & 0,297 & & 0,284 & 0,290 & 0,278 \\
\hline
\end{tabular}

Assim, para calcular o alfa de Cronbach, retirou-se os nove itens citados e os resultados foram os seguintes: o primeiro e o segundo fator apresentaram $\alpha=$ 0,68 e $\alpha=0,73$, respectivamente. Já o terceiro e o quarto fator seguiram com $\alpha=0,64$. O alfa da escala de 27 itens foi de 0,78 , demonstrando que a referida escala apresenta índices aceitáveis de consistência interna, mesmo três fatores tendo alcançado cargas abaixo de 0,70 .
Após a análise psicométrica do instrumento, buscou-se analisar as pontuações máximas e mínimas alcançadas na escala de estratégias, considerando-se todos os itens. No que concerne à pontuação geral, os resultados indicaram que a média obtida pelos participantes na escala foi 65,67 pontos $(\mathrm{DP}=12,07)$, sendo o valor mínimo 37 pontos e o máximo 95 pontos. Em seguida, buscou-se verificar a frequência com que os estudantes reportaram utilizar as estratégias. Na Tabela 3, têm-se a distribuição de todas as estratégias e suas respectivas frequências de uso.

Tabela 3

Distribuição das estratégias de aprendizagem por frequência de utilização

\begin{tabular}{|c|c|c|c|c|}
\hline & Sempre & Às vezes & Raramente & Nunca \\
\hline 1. Repetir as informações oralmente na medida em que vai lendo o texto. & $15,9 \%$ & $44,7 \%$ & $25,6 \%$ & $13,8 \%$ \\
\hline 2. Anotar na íntegra as explicações do professor. & $31,1 \%$ & $39,6 \%$ & $20,5 \%$ & $8,8 \%$ \\
\hline 3. Identificar suas dificuldades para aprender determinados tópicos ou assuntos. & $38,6 \%$ & $41,3 \%$ & $15,3 \%$ & $4,7 \%$ \\
\hline 4. Resumir os textos indicados para estudo. & $30,7 \%$ & $38,1 \%$ & $22,7 \%$ & $8,6 \%$ \\
\hline 5. Ler os textos indicados pelo professor. & $42,9 \%$ & $47,6 \%$ & $8,5 \%$ & $0,9 \%$ \\
\hline 6. Fazer anotações no texto ou em folha à parte. & $52,5 \%$ & $32,4 \%$ & $12,7 \%$ & $2,4 \%$ \\
\hline 7. Escrever com suas palavras o que entendeu do texto. & $22,1 \%$ & $34,8 \%$ & $30,7 \%$ & $12,4 \%$ \\
\hline 8. Ler textos complementares, além dos indicados pelo professor. & $5,9 \%$ & $31,3 \%$ & $40,4 \%$ & $22,4 \%$ \\
\hline 9. Motivar-se para as atividades de leitura e estudo. & $21,0 \%$ & $42,3 \%$ & $26,3 \%$ & $10,4 \%$ \\
\hline 10. Elaborar perguntas e respostas sobre o assunto estudado. & $5,0 \%$ & $23,9 \%$ & $31,0 \%$ & $40,1 \%$ \\
\hline 11. Selecionar as ideias principais do texto. & $50,3 \%$ & $32,0 \%$ & $14,5 \%$ & $3,3 \%$ \\
\hline 12. Controlar sua ansiedade em situações de avaliação. & $46,8 \%$ & $25,9 \%$ & $17,9 \%$ & $9,4 \%$ \\
\hline 13. Identificar o quanto você está ou não aprendendo. & $40,6 \%$ & $36,5 \%$ & $15,3 \%$ & $7,6 \%$ \\
\hline 14. Pedir auxílio ao professor sobre as dúvidas na matéria. & $27,1 \%$ & $40,3 \%$ & $27,1 \%$ & $5,6 \%$ \\
\hline 15. Rever as anotações feitas em sala de aula. & $57,4 \%$ & $30,9 \%$ & $9,1 \%$ & $2,6 \%$ \\
\hline 16. Procurar no dicionário o significado de palavras desconhecidas. & $27,6 \%$ & $32,6 \%$ & $23,5 \%$ & $16,2 \%$ \\
\hline 17. Pedir ajuda aos colegas em caso de dúvidas. & $48,2 \%$ & $37,6 \%$ & $12,4 \%$ & $1,8 \%$ \\
\hline 18. Administrar seu tempo de estudo. & $22,1 \%$ & $43,1 \%$ & $26,0 \%$ & $8,8 \%$ \\
\hline 19. Organizar seu ambiente de estudo. & $34,9 \%$ & $34,0 \%$ & $23,5 \%$ & $7,6 \%$ \\
\hline 20. Manter a calma diante de tarefas difíceis. & $36,0 \%$ & $41,3 \%$ & $14,7 \%$ & $8,0 \%$ \\
\hline 21. Recorrer a outros textos e livros sobre 0 assunto. & $18,9 \%$ & $47,0 \%$ & $26,9 \%$ & $7,1 \%$ \\
\hline 22. Planejar suas atividades de estudo. & $30,8 \%$ & $41,3 \%$ & $20,8 \%$ & $7,0 \%$ \\
\hline 23. Separar todo o material necessário para a tarefa que irá realizar. & $51,3 \%$ & $33,3 \%$ & $13,9 \%$ & $1,5 \%$ \\
\hline
\end{tabular}




\begin{tabular}{|c|c|c|c|c|}
\hline 24. Conseguir ir até o final de uma tarefa mesmo quando ela é difícil ou tediosa. & $22,6 \%$ & $52,7 \%$ & $20,5 \%$ & $4,2 \%$ \\
\hline 25. Verificar seus erros após receber uma nota de prova. & $48,7 \%$ & $30,4 \%$ & $16,8 \%$ & $4,1 \%$ \\
\hline 26. Tentar refazer questões que errou em uma prova. & $16,1 \%$ & $32,1 \%$ & $31,8 \%$ & $19,9 \%$ \\
\hline $\begin{array}{l}\text { 27. Distrair-se ou pensar em outra coisa quando está lendo, estudando ou } \\
\text { fazendo os trabalhos. }\end{array}$ & $3,2 \%$ & $11,8 \%$ & $43,8 \%$ & $41,2 \%$ \\
\hline 28. Ler suas respostas novamente antes de entregar a prova. & $51,3 \%$ & $34,0 \%$ & $11,4 \%$ & $3,2 \%$ \\
\hline 29. Estudar em grupo. & $12,7 \%$ & $35,8 \%$ & $34,6 \%$ & $16,9 \%$ \\
\hline 30. Anotar na agenda as coisas que tem para fazer. & $24,1 \%$ & $22,0 \%$ & $26,2 \%$ & $27,7 \%$ \\
\hline $\begin{array}{l}\text { 31. Fazer algum esquema no papel (esboço, gráfico ou desenho) para melhor } \\
\text { entender as relações entre eles. }\end{array}$ & $34,0 \%$ & $39,0 \%$ & $\%$ & $8,8 \%$ \\
\hline 32. Colar lembretes para recordar do que precisa fazer. & $23,0 \%$ & $26,5 \%$ & $22,1 \%$ & $28,3 \%$ \\
\hline 33. Discutir a matéria com os colegas para ver se entendeu. & $37,6 \%$ & $42,6 \%$ & $16,5 \%$ & $3,2 \%$ \\
\hline 34. Pedir para alguém tomar a matéria. & $5,9 \%$ & $27,4 \%$ & $32,9 \%$ & $33,8 \%$ \\
\hline 35. Reler a matéria para entendê-la melhor. & $44,0 \%$ & $40,8 \%$ & & $1,8 \%$ \\
\hline 36. Criar perguntas sobre o assunto que está estudando e tentar respondê-las. & $7,6 \%$ & $19,9 \%$ & $30,8 \%$ & $41,6 \%$ \\
\hline
\end{tabular}

Dando seguimento as análises estatísticas, como a distribuição dos dados foi tipicamente normal, executou-se o teste $t$ de Student para verificar diferenças entre as médias alcançadas pelos estudantes do sexo masculino e feminino. Assim, as mulheres obtiveram uma média de 67,74 (DP = 12,16) e os homens 62,60 (DP
$=11,31)$ e esta diferença foi estatisticamente significante $\mathrm{t}(339)=3,935, \mathrm{p}<0,001, \mathrm{r}=0,2$. Buscando aprofundar esse conhecimento, buscou-se analisar quais as estratégias que seriam utilizadas de forma diferente considerando o sexo (Tabela 4).

Tabela 4

Estratégias utilizadas diferentemente considerando o sexo dos participantes

\begin{tabular}{lc}
\hline & $r$ \\
\hline 1. Repetir as informações oralmente na medida em que vai lendo o texto. & $-0,252^{* *}$ \\
2. Anotar na íntegra as explicações do professor. & $-0,221^{* *}$ \\
4. Resumir os textos indicados para estudo. & $-0,293^{* *}$ \\
5. Ler os textos indicados pelo professor. & $-0,148^{* *}$ \\
6. Fazer anotações no texto ou em folha à parte. & $-0,273^{* *}$ \\
12. Controlar sua ansiedade em situações de avaliação. & $0,216^{* *}$ \\
15. Rever as anotações feitas em sala de aula. & $-0,171^{* *}$ \\
18. Administrar seu tempo de estudo. & $-0,186^{* *}$ \\
19. Organizar seu ambiente de estudo. & $-0,253^{* *}$ \\
20. Manter a calma diante de tarefas difíceis. & $0,296^{* *}$ \\
22. Planejar suas atividades de estudo. & $-0,116^{*}$ \\
23. Separar todo o material necessário para a tarefa que irá realizar. & $-0,156^{* *}$ \\
30. Anotar na agenda as coisas que tem para fazer. & $-0,358^{* *}$ \\
31. Fazer algum esquema no papel (esboço, gráfico ou desenho) para melhor entender as relações entre eles. & $-0,125^{*}$ \\
32. Colar lembretes para recordar do que precisa fazer. & $-0,355^{* *}$ \\
34. Pedir para alguém tomar a matéria. & $-0,171^{* *}$ \\
\hline
\end{tabular}

${ }^{*} p<0,05 ;{ }^{* *} p<0,01$

Buscou-se verificar também se haveria diferenças entre os grupos quando comparadas as áreas de conhecimento (Exatas, Humanas e Saúde). Os estudantes da área de Exatas alcançaram uma média de 64,69 (DP $=11,97)$, os de Humanas 66,40 (DP $=12,33)$ e os de Saúde 66,06 (DP = 11,28). A análise de variância (ANOVA) revelou não existir diferença estatistica- mente significativa entre esses grupos $(\mathrm{F}(2 ; 338)=$ $0,783 ; \mathrm{p}=0,458)$.

\section{DISCUSSÃO}

No que concerne às propriedades psicométricas da escala, a estrutura de quatro fatores mostrou-se mais adequada teoricamente, embora alguns itens ainda 
tenham carregado no fator não esperado ou em mais de um fator. Por exemplo, os fatores Estratégias de Controle Interno e Externo e Estratégias de Interação Social alcançados no presente estudo se assemelharam aos fatores Autorregulação dos Recursos Internos e Contextuais e Autorregulação Social obtidos no estudo de validação inicial. Enquanto os fatores Estratégias de Armazenamento da Informação e Estratégias de Busca e Seleção da Informação passaram a ser uma divisão do fator Autorregulação Cognitiva e Metacognitiva, originalmente proposto. Supõe-se que isso ocorreu, pois no estudo de validação o primeiro fator comportava 24 itens, mostrando-se muito abrangente, capaz de englobar itens teoricamente diferentes, tanto cognitivos como metacognitivos. Frente a esse resultado, sugere-se que novas pesquisas, buscando as evidências de validade, sejam realizadas.

Quanto à pontuação na escala de estratégias, percebeu-se que a média obtida pelos participantes foi de 65,67 pontos, sendo o valor mínimo 37 pontos e o máximo 95 pontos. Alcará (2012), utilizando-se da mesma versão da escala, encontrou uma pontuação média 68,29, mínimo de 41 e máximo de 96 pontos. Tal resultado aponta que, em ambos os estudos, os alunos apresentaram resultados acima de $50 \%$ da pontuação máxima. Mas, ao analisar a frequência com que os estudantes reportavam utilizar a maioria das estratégias, constatou-se que boa parte dos alunos utiliza tanto as estratégias cognitivas como as metacognitivas apenas "às vezes".

Diante disso, tem-se que os estudantes universitários utilizam estratégias de aprendizagem durante o estudo, mas o fazem com uma frequência aquém do esperado. Pode-se pensar que os estudantes conhecem as estratégias de aprendizagem, mas não as utilizam com a frequência adequada, ou porque não entendem o significado e importância dessas estratégias para a aprendizagem, ou porque ainda não sabem como usá-las em seu cotidiano a fim de obter resultados melhores.

Nesse sentido, Silva e Sá (1997) apontam que para que os estudantes sejam bem sucedidos, precisam compreender a utilidade das estratégias de aprendizagem. Assim sendo, uma opção para reverter o quadro seria, além de mostrar aos estudantes quais as estratégias que podem auxiliá-los, explicar como elas interferem positivamente no processo de aprendizagem. Assim, poder-se-ia ajudar os estudantes a modificarem hábitos enraizados, fazendo com que novos comportamentos fossem aprendidos.
No que concerne ao sexo dos respondentes, analisando a pontuação geral na escala de estratégias de aprendizagem, foi verificada uma diferença significativa entre os sexos, tendo as mulheres apresentado uma média de pontos maior do que os homens. Estas reportaram utilizar com mais frequência estratégias como "fazer anotações no texto ou em folha à parte", "rever as anotações feitas em sala de aula", "organizar seu ambiente de estudo" e "anotar na agenda as coisas que tem para fazer", enquanto os homens reportaram usar mais frequentemente estratégias como "identificar suas dificuldades para aprender determinados tópicos ou assuntos", "controlar sua ansiedade em situações de avaliação" e "manter a calma diante de tarefas difíceis". Tal dado corrobora os achados de Bartalo (2006), Bartalo e Guimarães (2008), Joly e Paula (2005), Bortoletto (2011) e Silva (2012) que também verificaram diferenças no desempenho de homens e mulheres, em favor dessas. Diferentemente, Alcará (2012) não encontrou diferença estatisticamente significante entre os sexos, tendo os homens obtido escores mais elevados em duas subescalas e na pontuação total.

Ainda não está suficientemente claro o que leva a essa diferenciação entre homens e mulheres no uso de estratégias de aprendizagem. Silva (2012) imagina que isso ocorra, pois as mulheres são mais automotivadas para os estudos e demonstram maior empenho em realizar as tarefas de aprendizagem, permanecendo inclusive mais tempo na escola do que os homens. Lins, Araujo e Minervino (no prelo) supõe que essa diferença pode ocorrer graças a questões inerentes ao desenvolvimento humano, uma vez que as mulheres amadurecem primeiro e por se desenvolverem socialmente, emocionalmente e mentalmente mais cedo, podem usufruir do entendimento adquirido acerca das estratégias de aprendizagem com mais eficácia.

Já no que diz respeito às áreas do conhecimento, analisando a pontuação geral obtida, não foi verificada uma diferença significativa entre as áreas, assim como em Joly e Paula (2005). Comparando os cursos de Biblioteconomia e Arquivologia, Bartalo (2006), Bartalo e Guimarães (2008) e Alcará (2012), não encontraram diferença significativa entre os dois cursos (ambos da área de humanas), mas as primeiras verificaram diferenças entre os dois cursos e outros das áreas de exatas e saúde. Muneiro (2008) encontrou diferenças ao comparar alunos dos cursos de Serviço Social (humanas) e Engenharia de Produção (exatas). 
Silva (2012) também encontrou diferenças estatisticamente significantes no fator de autorregulação dos recursos internos e contextuais ao comparar os grupos por área do conhecimento.

Diante desse resultado distinto, imagina-se que, mesmo as diferentes áreas de conhecimento demandando uma organização de informações individualizadas e, portanto, estratégias de aprendizagem diferenciadas, os respondentes desta pesquisa, por possuírem um repertório de estratégias adquirido ao longo da sua vida escolar, podem não se permitir aprender novas estratégias ou não ter oportunidade para tal. Nesse sentido, novamente a necessidade de ofertar aos alunos chances para conhecer e aprender a utilizar as estratégias de aprendizagem, como recomenda Bartalo e Guimarães (2008), é ressaltada.

Além desses resultados, evidencia-se que algumas questões como, por exemplo, "pedir para alguém tomar a matéria", "fazer algum esquema no papel (esboço, gráfico ou desenho) para melhor entender as relações entre eles", "motivar-se para as atividades de leitura e estudo", mostraram-se confusas para os estudantes, tendo levantado questionamentos no momento da aplicação. Por exemplo, na primeira questão citada muitos tiveram dúvidas sobre o que seria "tomar a matéria" em virtude dessa não ser uma expressão comumente usada na graduação. Já na segunda, alguns não compreenderam a que se referia o "eles" ao final da expressão e na terceira, o que significaria motivarse (ficar o tempo todo repetindo para si: "vamos lá, você consegue!"?). Por essa razão, sugere-se que as questões sejam modificadas, de modo a dirimir possíveis dúvidas.

\section{CONSIDERAÇÕES FINAIS}

De forma geral, os resultados demonstram que a escala apresenta um índice aceitável de confiabilidade interna, mas novas pesquisas são requisitadas para que se possa definir melhor a estrutura de fatores do instrumento e também buscar outros indícios de validade. Fatores como sexo afetam o uso e o nível de desenvolvimento de algumas estratégias de aprendizagem, embora o mesmo possa não ocorrer com as áreas do conhecimento. Contudo, uma limitação deste estudo é que a amostra não foi homogênea, nem representativa de todos os cursos. Por essa razão, é preciso cautela ao analisar os resultados aqui apresentados e recomendase que pesquisas, abarcando um número maior de estudantes de todos os cursos sejam realizadas a fim de buscar verificar os resultados aqui expostos.

\section{REFERÊNCIAS}

Alcará, A. R. (2012). Compreensão de leitura, estratégias de aprendizagem e motivação em universitários: estudo de validade de medidas. (Tese de Doutorado). Universidade São Francisco, Itatiba, SP.

Bartalo, L. (2006). Mensuração de estratégias de estudo e aprendizagem de alunos universitários: learning and study strategies inventory (LASSI) adaptação e validação para o Brasil. (Tese de Doutorado). Universidade Estadual Paulista, Marília, SP.

Bartalo, L., \& Guimarães, S. E. R. (2008). Estratégias de estudo e aprendizagem de alunos universitários: um estudo exploratório. Informação \& Informação, 13(2), 1-14.

Bortoletto, D. (2011). Estratégias de aprendizagem e de regulação emocional de estudantes dos cursos de formação de professores. (Dissertação de Mestrado). Universidade Estadual de Campinas, Campinas, SP.

Boruchovitch, E. (1999). Estratégias de Aprendizagem e Desempenho Escolar: Considerações para a Prática Educacional. Psicologia: Reflexão e Crítica, 12(2), 361-376.

Boruchovitch, E. (2001). Algumas Estratégias de Compreensão em Leitura de Alunos do Ensino Fundamental. Psicologia Escolar e Educacional, 5(1), 19-25.

Boruchovitch, E. (2006). Avaliação Psicoeducacional: Desenvolvimento de instrumentos à luz da psicologia cognitiva baseada na teoria do processamento da informação. Avaliação Psicológica, 5(2), 145-152.

Costa, E. R. (2000). Estratégias de aprendizagem e a ansiedade de alunos do ensino fundamental: implicações para a prática educacional. (Dissertação de Mestrado). Universidade Estadual de Campinas, Campinas, SP.

Dansereau, D. F.; Collins, K. W.; McDonald, B. A.; Holley, C. D.; Garland, J.; Diekhoff, G.; Evans, S. H. (1979). Development and Evaluation of a Learning Strategy Training Program. Journal of Educational Psychology, 71(1), 64-73.

Dembo, M. H. (1994). Applying educational psychology. New York: Longman Publishing Group.

Joly, M. C. R. A., \& Paula, L. M. (2005). Avaliação do uso de estratégias de aprendizagem e a compreensão em leitura de universitários. In M. C. R. A. Joly, A. A. A. Santos \& F. F. Sisto (Orgs.). Questões do cotidiano universitário (pp.33-58). São Paulo, SP: Casa do Psicólogo.

Lins, M. R. C, Araujo, M. R., \& Minervino, C. A. S. M. (no prelo). Estratégias de aprendizagem utilizadas por meninos e meninas: análise comparativa. Psicologia Argumento.

Muneiro, M. L. (2008). Estratégias de aprendizagem de alunos do ensino superior. (Dissertação de mestrado). Universidade Estadual de Campinas, Campinas, SP.

Pozo, J. I. (1996). Estratégias de aprendizagem. In C. Coll, J. Palácios \& A. Marchesi (Orgs.). Desenvolvimento psicológico 
e educação: psicologia da educação (pp. 176-197). Tradução de Angélica Mello Alves. Porto Alegre, RS: Artes Médicas.

Pozo, J. I., Monereo, C., \& Castelló, M. (2004). O uso estratégico do conhecimento. In C. Coll, A. Marchesi \& J. Palacios (Orgs.). Desenvolvimento psicológico e educação (pp. 145160). Tradução de Fátima Murad. Porto Alegre, RS: Artes Médicas.

Santos, A. A. A., \& Boruchovitch, E. (2011). Estudos para a elaboração da Escala de Avaliação de Estratégias de Aprendizagem para Universitários. Relatório técnico não publicado. Universidade São Francisco e Unicamp, São Paulo.

Sélis, P. S. (2008). Compreensão em leitura e estratégias de aprendizagem em universitários. (Dissertação de Mestrado). Universidade do Oeste Paulista, Presidente Prudente, SP.

Silva, L. L. V. (2012). Estilos e estratégias de aprendizagem de estudantes universitários. (Dissertação de Mestrado). Universidade de São Paulo, São Paulo, SP.

Silva, A. L., \& Sá, I. (1997). Saber estudar e estudar para saber. Coleção Ciências da Educação. Porto, Portugal: Porto Editora.
Weinstein, C., \& Mayer, R. (1983). The Teaching of Learning Strategies. Innovation Abstracts, 5(32).

Zenorini, R. P. C. (2002). Avaliação das metas de realização $e$ das estratégias de aprendizagem em universitários. (Dissertação de Mestrado). Universidade São Francisco, Itatiba, SP.

Zimmerman, B. J., \& Martinez-Pons, M. (1986). Development of a structured interview for assessing student use of selfregulated learning strategies. American Educational Research Journal, 23, 614-628.
Recebido em 14/10/2012 Primeira Decisão Editorial em 03/06/2013 Aceito em 20/03/2013 